\title{
Malnutrition and Dental Caries: A Review of the Literature
}

\author{
W.J. Psoter ${ }^{\mathrm{a}, \mathrm{c}}$ B.C. Reid ${ }^{\mathrm{b}}$ R.V. Katz ${ }^{\mathrm{a}}$ \\ ${ }^{a}$ Department of Epidemiology and Health Promotion, New York University College of Dentistry, New York, N.Y., \\ ${ }^{b}$ Department of Health Promotion and Policy, University of Maryland, School of Dentistry, Baltimore, Md., and \\ ${ }^{c}$ School of Dentistry, University of Puerto Rico, Río Piedras, P.R., USA
}

\section{Key Words}

Dental caries $\cdot$ Malnutrition $\cdot$ Review

\begin{abstract}
Protein-energy malnutrition occurs when there are deficiencies in protein, energy foods or both, relative to a body's needs. This paper reviews the association of early childhood malnutrition with: (1) dental caries, (2) enamel hypoplasia, (3) salivary gland hypofunction, and (4) delayed eruption. Studies suggest that caries of the primary dentition is associated with early childhood malnutrition, though the effect on caries of the permanent dentition has essentially not been studied. Enamel hypoplasia, salivary glandular hypofunction and saliva compositional changes may be mechanisms through which malnutrition is associated with caries, while altered eruption timing may create a challenge in the analysis of agespecific caries rates.
\end{abstract}

Copyright (c) 2005 S. Karger AG, Basel

Protein-energy malnutrition (PEM) occurs when there are deficiencies in protein, energy foods or both, relative to a body's needs [Shils et al., 1999]. 'Dietary energy and protein deficiencies usually occur together' [Shils et al., 1999]. Mild PEM has an acute course and has a main de- ficiency in energy; moderate PEM is chronic in nature and has a main deficiency in protein, while severe PEM is both chronic and acute, and is composed of deficiencies in both protein and energy [Shils et al., 1999]. PEM can be viewed as universally similar in its clinical manifestations in terms of its relative protein and energy contributions for a given frequency and magnitude of the deficiencies.

However, PEM during the first 5 years of life cannot be viewed solely in terms of nutritional intake. '[Malnutrition] refers to the syndrome of inadequate intakes of protein, energy, and micronutrients, combined with frequent infections' [Semba and Bloem, 2001]. Over a third of the world's children are affected by PEM [Onis et al., 2001], which results in a lower resistance to diseases [WHO, 1996]. Of over 13 million annual childhood deaths, it has been estimated that more than one half are associated with PEM, and that three quarters of these deaths are in children with only mild to moderate PEM [UNICEF, 1995].

PEM, while generally considered a health problem in developing countries, is not rare in developed countries. A $1 \%$ prevalence of frank malnutrition in children under 5 years old (almost 200,000 children) is reported for the US [Census Bureau, 2001; UNICEF, 1999]. Ten percent of US households report food insecurity with 3\% classified as severe insecurity (insecurity defined as not always having access to enough food for a healthy life, severe in-

\section{KARGER}

(ㄱ) 2005 S. Karger AG, Basel

Fax +41613061234

E-Mail karger@karger.ch

www.karger.com
Accessible online at: www.karger.com/cre
Walter J. Psoter, DDS, PhD

New York University College of Dentistry

Department of Epidemiology and Health Promotion, 345 East 24th Street

New York, NY 10010 (USA)

Tel. +1 212998 9217, Fax +1 212995 4087, E-Mail wp9@nyu.edu 
security as experiencing hunger) [USDA, 2000], with poor nutrition disproportionately concentrated in citizens that are African-American, poor and less educated [Bowman et al., 1998]. Reports of underweight and stunted children, a result of inadequate nutrition, range from 3.3 through $21 \%$ for various US regions and populations [Carvalho et al., 2001; Crooks, 1999; Wiecha and Casey, 1994]. Thus, scientifically sound studies of malnutrition and health outcomes, particularly those that distinguish a gradient of nutritional levels, have direct and immediate applicability to the health of children worldwide.

In order to consider oral outcomes possibly associated with PEM, a brief synopsis of caries biology, based on the excellent review of Seow [1998], is presented. Biological factors of caries are: (1) cariogenic bacteria in a complex ecological system (plaque); (2) fermentable carbohydrates, and (3) host factors. Cariogenic bacteria produce acid using fermentable carbohydrates that demineralizes the tooth. Base-producing bacteria and remineralizing activity may modify or counter the produced acid effects. However, more pertinent in terms of PEM are the host factors associated with caries, specifically tooth defects and the salivary system.

Tooth defects of interest are external structural defects (hypoplasia) that can provide a more cariogenic environmental niche and less protective enamel and defects that include hypomineralization and might increase susceptibility to demineralization. Salivary flow rates are related to caries directly through oral clearance and in terms of buffering capacity and antimicrobial components. Salivary buffering is mediated by the carbonate-bicarbonate system, as well as phosphate and protein systems. Salivary antimicrobial activities include both an effect on microbial adhesion and colonization of the tooth surface, and specific antimicrobial proteins. These proteins include lysozyme, lactoferrin, peroxidase enzymes, and histidine-rich proteins. Further, components of saliva such as mucins, glycoproteins, fibronectin, $\beta_{2}$-macroglobulin, lysozyme and s-IgA may agglutinate bacteria and aid in their clearance. Additionally, although salivary and crevicular immunoglobulins are present, little is known of their effective anticaries activities.

This paper reviews the literature on the association of early childhood malnutrition with dental caries, as well as the evidence that enamel hypoplasia and salivary gland hypofunction may be underlying explanatory mechanisms for the effect of PEM on dental caries. Further, this paper reviews the literature on altered eruption timing as a potential confounding or explanatory variable in the relationship between PEM and dental caries.

\section{Methods}

The Medline database was searched for English-language articles, published over the period 1966-2003 for the topics of malnutrition, PEM, caries, enamel hypoplasia, tooth eruption, oral, dental, and saliva/salivary function. Hand searching was additionally conducted from the citations of the identified reports. The intent of this literature search was to identify and review the analytic reports of malnutrition and dentition and salivary outcomes and include all peer-reviewed epidemiological and supporting animal scientific articles in this review.

\section{Results}

Dental Caries

Experimental investigations in rats of associations between PEM and dental caries have demonstrated increased caries levels with both pre- and postnatal nutritional deficiencies [Harris and Navia, 1980; Johansson et al., 1985; Menaker and Navia, 1973a; Shaw and Griffiths, 1963]. Menaker and Navia [1973a] showed this association to be with protein rather than caloric malnutrition, while Harris and Navia [1980] showed increased caries in vitamin A-deficient rats. A mechanism for this increased caries susceptibility was hypothesized to be through increased enamel solubility [Aponte-Merced and Navia, 1980].

Several studies in Guatemala [Infante and Gillespie, 1976, 1977; Sweeney and Guzman, 1966; Sweeney et al., 1971] and one among Thai children [Kanchanakamol et al., 1996], taken in aggregate, have suggested positive relationships between malnutrition, enamel hypoplasia and primary dentition caries. A few other studies have provided more direct evidence of a PEM-primary dentition caries association. Three cross-sectional studies showed increased primary dentition caries levels in stunted children [Alvarez et al., 1988; Cleaton-Jones et al., 2000; Li et al., 1996], and two additional cross-sectional studies have shown this increase in primary dentition caries to be associated with wasted, and wasted and stunted children [Alvarez et al., 1990; Cleaton-Jones et al., 2000]. Two of these studies accounted for confounding due to the delayed eruption of primary teeth in malnourished children [Alvarez et al., 1988, 1990]; while no study adequately controlled for other possible confounding variables, e.g., sugar consumption, with the exception of $\mathrm{Li}$ et al. [1996].

A longitudinal study in Peru, adjusting for delayed eruption through the comparison of peak caries levels, suggested that a single, prolonged, mild to moderate mal- 
nutrition episode in the first year of life may result in higher primary dentition caries rates, an increase in permanent dentition caries and that the caries risk may be mediated by means other than enamel hypoplasia [Alvarez et al., 1993, 1995]. This study provides the sole evidence of a relationship between early childhood PEM and permanent dentition caries.

\section{Enamel Hypoplasia (EH)}

Epidemiological studies have suggested associations between caries, enamel hypoplasia and PEM [Enwonwu, 1973; Infante and Gillespie, 1977; Kanchanakamol et al., 1996; Li et al., 1996; Matee et al., 1992; Pascoe and Seow, 1994; Sweeney and Guzman, 1966; Sweeney et al., 1971]. The reported EH association with increased caries suggested a pathway between malnutrition and dental caries. However, study designs, primarily cross-sectional, limit the strength of this evidence for both the primary and permanent dentition.

The geographic distribution of $\mathrm{EH}$ is worldwide in developing nations [Jontell and Linde, 1986] and is associated with lower socioeconomic status [Enwonwu, 1973; Sweeney et al., 1971]. Goodman et al. [1991] reported $15-70 \%$ prevalence of permanent anterior dentition $\mathrm{EH}$ and found that the prevalence varies between specific teeth.

As classically described in the malnutrition-caries literature, $\mathrm{EH}$ is a lesion characterized by hypoplastic grooves and/or pits in the enamel, often horizontal or linear in appearance. More recently, the World Health Organization (WHO) has defined diagnostic criteria expanding this case definition to include enamel opacities [WHO, 1997] and detailed discussions of these criteria have been published [Clarkson and O'Mullane, 1989].

Suckling et al. [1983] demonstrated an association between $\mathrm{EH}$ and both micronutrient and general malnutrition. These investigators induced a nutritional disorder in sheep by the introduction of nematode parasites and demonstrated a relationship between the timing of the malnutrition and the location of the enamel hypoplastic lesion, suggesting a correspondence between the timing of the malnutrition and the disruption of enamel maturation and development. Experiments using rats have shown no EH and protein deficiency relationship, but a demonstrated non-EH alteration of rat surface enamel has been observed [Aponte-Merced and Navia, 1980]. Enamel alterations in animal models have also been observed for vitamin A [Mellanby, 1942], vitamin D, and calcium deficiencies [Jontell and Linde, 1986].
Human studies have observed an association between early childhood malnutrition and $\mathrm{EH}$ in primary teeth using various study designs, mostly cross-sectional [Goodman and Armelagos, 1985; Goodman et al., 1991; Infante and Gillespie, 1977; Matee et al., 1992, 1994; May et al., 1993; Nikiforuk and Fraser, 1981; Schamschula et al., 1980; Sweeney and Guzman, 1966; Sweeney et al., 1969, 1971]. These studies have generally been limited in their analyses, having little if any ability to control for confounding. For example, three of these reports also describe EH in the permanent dentition, but used supplementation given to mothers or socioeconomic status as a proxy for malnutrition. Further, these studies have largely defined $\mathrm{EH}$ as hypoplastic grooves and/or pits in the enamel or do not distinguish between structural lesion and developmental enamel opacities. Notably, RuggGunn et al. [1998] found concurrent malnutrition in 2- to 6-year-old Saudi males associated with both case definitions of EH (structural and opacities), while controlling for a variety of potential confounders. Only this report and that of Li et al. [1996] utilized multivariate modeling to control for possible confounders such as low birth weight.

Sweeney et al. [1969] suggested an association between infectious disease in the first 35 days of life and $\mathrm{EH}$ of primary teeth. Using their data, we have computed an odds ratio (OR) for $\mathrm{EH}$ of 3.3 (CI 1.05, 10.5) for those children with an infection in the first 35 days of life. This OR is reduced slightly to 2.9 when controlled for birth prematurity. This finding suggests either a direct effect of infections on $\mathrm{EH}$, possibly through febrile responses, or an indirect effect, i.e. infections being markers for malnutrition rather than an etiological risk factor for $\mathrm{EH}$.

In simple terms, EH has been associated with caries development as it may provide a mechanical nidus for bacteria and food [Infante and Gillespie, 1977; Kanchanakamol et al., 1996; Li et al., 1996; Matee et al., 1992, 1994; Schamschula et al., 1980; Sweeney and Guzman, 1966; Sweeney et al., 1971]. This external EH may reflect and/or be a marker for tooth external and/or internal hypomineralization or alterations in enamel composition; EH is observed in studies of neonatal calcium homeostasis disorders, as subjects with these disorders have demonstrated an association with EH [Jontell and Linde, 1986]. However, no studies of malnutrition-associated hypoplasia/hypomineralization structural or chemical properties in humans have been reported, in fact 'little is known of the microscopic structure of teeth with developmental defects' [Fearne et al., 2004]. Inference regarding such properties can be made from two laboratory 
studies by Fearne et al. One study, a three-dimensional $\mathrm{X}$-ray microscopic study of 'idiopathic enamel hypoplasia', found a $20 \%$ decrease in mineralization of both structural and opacity hypoplastic enamels that extended throughout the depth of the enamel [Fearne et al., 2004]. An earlier study had reported a $10 \%$ decrease in mineralization in primary dentition developmental defects of low birth weight children [Fearne et al., 1994]. As noted by Aoba [2004], the extent of mineralization of enamel affects its solubility in an acid environment, and suggests another mechanism other than a structural bacterial niche, for any association between enamel hypoplasia and caries. A recent comprehensive review on the demineralization-remineralization of teeth published by Robinson et al. [2000] may be of interest for further background information.

In summary, animal studies suggest nutritional deficiencies as a mechanism to explain $\mathrm{EH}$, demonstrating that both general and specific nutritional deficiencies can cause enamel alteration. In humans malnutrition in early childhood is associated with $\mathrm{EH}$ of the primary dentition both of the classic, structural hypoplasia and with more limited evidence, for enamel opacities; there is weaker support for an EH association with the permanent dentition due to a limited number of studies, potential malnutrition misclassification and confounding. The few studies of EH properties, and those of hypoplasia/hypomineralization not associated with known nutritional deficiencies in humans, suggest a decreased mineralization surface and subsurface of enamel affected by PEM.

\section{Salivary Gland Hypofunction}

Salivary gland hypofunction may be defined by decreased saliva flow rate, decreased buffering capacity, and decreased salivary constituents, particularly proteins. In general, animal studies support an association between PEM and salivary hypofunction [Deichtman et al., 1980; Johansson et al., 1985; Menaker and Navia, 1973b, 1974; Watson and Antal, 1980; Winick and Noble, 1966]. In aggregate, these studies report decreased submandibular gland weight, saliva flow, and salivary proteins in malnourished animals.

Johansson et al. [1985] reported that in rats total protein, lysozyme, lactoperoxidase and immunoglobulins were all depressed under conditions of malnutrition. There are a limited number of studies investigating malnutrition and salivary hypofunction in humans [Agarwal et al., 1984; Azzopardi and Watson, 1986; Johansson et al., 1984, 1992, 1994; McMurry et al., 1977]. An early study by McMurry et al. [1977] indicated that malnour- ished children in Colombia had a markedly reduced rate of salivary secretion and of $\operatorname{IgA}$ in both saliva and tears. A subsequent study by Agarwal et al. [1984] found that among a sample of Indian children the salivary protective constituents including overall protein levels and specifically amylase, lysozyme, and immunoglobulins displayed a dose-response pattern with PEM. Azzopardi and Watson [1986] found that Gambian children had significantly lower salivary IgA than comparable British children and attributed the differences to malnutrition among the Gambian children. A later investigation by Johansson et al. [1992] linked malnutrition in children with reduced stimulated salivary flow rate, buffering capacity, and caries incidence, but observed that resting salivary flow rate was not affected. These findings were supported and expanded in a latter study that found Indian children with moderate to severe PEM had a reduced salivary secretion rate, reduced buffering capacity, lower calcium, and lower protein secretion in stimulated saliva, and reduced agglutinating defense factors in unstimulated saliva than Indian children with no or mild PEM [Johansson et al., 1994].

These studies, albeit in small groups of children, clearly indicate the possibility of a link between PEM, salivary flow rates, buffering capacity and the protein composition/content of saliva. This reduced function may increase caries risk and offers a mechanism that may partially explain an association of caries with PEM.

\section{Altered Eruption Timing}

The importance of altered eruption timing of the teeth is that an advanced or delayed eruption would increase or decrease, respectively, the age-specific exposure time to cariogenic conditions, so age-specific caries rates may be confounded by altered eruption. An association of delayed eruption with malnutrition has been observed in rats fed protein- or protein- and calorie-deficient diets [DiOrio et al., 1973; Shaw and Griffiths, 1963]. Delayed eruption of deciduous teeth in humans was observed in twelve cross-sectional studies and two concurrent cohort studies [Alvarez et al., 1988, 1990, 1995; Barrett and Brown, 1966; el Lozy et al., 1975; Enwonwu, 1973; Kanawati and McLaren, 1973; McGregor et al., 1968; Mukherjee, 1973; Neil et al., 1973; Rami Reddy et al., 1986; Sweeney and Guzman, 1966; Toverud, 1956; Visweswara et al., 1973]. In contrast, three other crosssectional studies and one concurrent cohort study found little to no association of eruption times of primary teeth with malnutrition [Delgado et al., 1975; Rami Reddy, 1981; Robinow, 1973; Truswell and Hansen, 1973]. 
Only two studies of early childhood malnutrition have recorded eruption times of permanent teeth and they report conflicting results, one reporting advanced eruption of the permanent incisors and first molars, the other finding no difference in eruption ages [Alvarez, 1995; Toverud, 1956]. The overall picture is of a likely association between malnutrition and delayed eruption of primary teeth but no firm association between early childhood malnutrition and the age of eruption of the permanent teeth.

\section{Conclusion}

Primary dentition caries has been associated with early childhood malnutrition, though an effect on permanent dentition caries is as yet not established because of the small number of scientific studies. Investigations of PEM and the primary dentition need to take delayed eruption into account and studies of PEM and the permanent dentition need to be cognizant of possible altered eruption timing of the permanent teeth, which create a challenge in the analysis of age-specific caries rates.

Although the majority of the studies we report here consider few confounders, investigations of PEM and both $\mathrm{EH}$ and salivary hypofunction suggest a possible biological mechanism for a PEM-caries association. Reports provide a significant body of evidence associating early childhood PEM and external EH in the primary dentition, though the association with the permanent teeth is less substantiated. Internal and subclinical hypoplasia is hypothesized but not reported in regards to PEM-associated enamel defects. External EH/hypomineralization may create a surface that is more retentive to a pathogenic microbial flora, and there is some indirect evidence that any hypoplasia/hypomineralization may be structurally more susceptible to demineralization. Though studies are limited in number, changes in salivary flow, buffering and composition have been consistently reported to be associated with PEM. However, human studies have been cross-sectional and have not established a lasting PEM effect on salivary function that some animal studies suggest. Further, whether any such salivary changes increase caries susceptibility is unknown. The US National Institute of Dental and Craniofacial Research Caries Consensus Conference's systematic review of the physical and chemical aspects of saliva and dental caries reports that there is no convincing evidence of caries associations with salivary small molecules, immunoglobulins or innate non-immunoglobulin factors (primarily the proteins) [Leone and Oppenheim, 2001]. Thus, detailed PEM saliva studies may provide evidence for an association of such salivary components with caries and generate hypotheses on the interactions of the various protective mechanisms.

Overall, longitudinal studies of the oral outcomes associated with early childhood malnutrition that control for known confounders and focused research on the detailed biological mechanisms would benefit our scientific knowledge base and have broader applications in dentistry and medicine.

\section{Acknowledgment}

Preparation of the manuscript was supported by the grant NIH NIDCR R01 DE014708-01A2.

\section{References}

\footnotetext{
Agarwal PK, Agarwal KN, Agarwal DK: Biochem- Alvarez JO, Lewis CA, Saman C, Caceda J, Monical changes in saliva of malnourished children. Am J Clin Nutr 1984;39:181-184

Alvarez JO: Nutrition, tooth development, and dental caries. Am J Clin Nutr 1995;61:410S$416 \mathrm{~S}$.

Alvarez JO, Caceda J, Woolley TW, et al: A longitudinal study of dental caries in the primary teeth of children who suffer from infant malnutrition. J Dent Res 1993;72:1573-1576. talvo J, Figueroa ML: Chronic malnutrition, dental caries, and tooth exfoliation in Peruvian children aged 3-9 years. Am J Clin Nutr 1988 48:368-372.

Aoba T: Solubility properties of human tooth mineral and pathogenesis of dental caries. Oral Dis 2004; 10:249-257.

Aponte-Merced L, Navia JM: Pre-eruptive protein-energy malnutrition and acid solubility of rat molar enamel surfaces. Arch Oral Biol 1980;25:701-705. effect of nutritional status on the age distribution of dental caries in the primary teeth. $\mathrm{J}$ Dent Res 1990;69:1564-1566.

Azzopardi D, Watson JG: Gambian children have less salivary secretory immunoglobulin A than British children. J Trop Pediatr 1986;32:120 122.

Barrett MJ, Brown T: Eruption of deciduous teeth in Australian aborigines. Aust Dent J 1966;11: 43-50.

Bowman SA, Lino M, Ferrior SA, Basiotis PP: The healthy eating index: 1994-96. USDA, 1998.

Carvalho N, Tomashek K, Parashar U, Powell K, Mellinger-Birdsong A: Severe malnutrition among young children - Georgia, January 1997-June 1999. MMWR Morb Mortal Wkly Rep 2001:50:224-227.

Census Bureau: Population Estimates. US Census Bureau, 2001, www.census.gov/population/estimates/nation/intfile2-1.txt.

Clarkson J, O’Mullane D: A modified DDE Index for use in epidemiological studies of enamel defects. J Dent Res 1989;68:445-450.
} 
Cleaton-Jones P, Richardson BD, Granath L, Fatti LP, Sinwell R, Walker AR, Mogotsi M: Nutritional status and dental caries in a large sample of 4- and 5-year-old South African children. S Afr Med J 2000;90:631-635.

Crooks DL: Child growth and nutritional status in a high-poverty community in eastern Kentucky. Am J Phys Anthropol 1999;109:129_ 142.

Deichtman GC, Antal M, Watson JG: Concentrations of immunoglobulin $\mathrm{G}$ and amylase in saliva of moderately protein undernourished rats. J Food Sci 1980;45:1092-1095.

Delgado H, Habicht JP, Yarbrough C, Lechtig A, Martorell R, Malina RM, et al: Nutritional status and the timing of deciduous tooth eruption. Am J Clin Nutr 1975;28:216-224.

DiOrio LP, Miller SA, Navia JM: The separate effects of protein and calorie malnutrition on the development and growth of rat bones and teeth. J Nutr 1973;103:856-865.

- ${ }^{2}$ Lozy M, Reed RB, Kerr GR, Boutourline E, Tesi G, Ghamry MT, et al: Nutritional correlates of child development in southern Tunisia. Growth 1975;39:209-221.

Enwonwu CO: Influence of socio-economic conditions on dental development in Nigerian children. Arch Oral Biol 1973;18:95-107.

-Fearne J, Anderson P, Davis GR: 3D X-ray microscopic study of the extent of variations in enamel density in first permanent molars with idiopathic enamel hypomineralization. $\mathrm{Br}$ Dent J 2004;196:634-638.

- Fearne JM, Elliot JC, Wong FSL, Davis GR, Boyde A, Jones SJ: Deciduous enamel defects in low birthweight children: Correlated X-ray microtomographic and backscattered electron imaging study of hypoplasia and hypomineralization. Anat Embryol 1994; 189:375-381.

-Goodman AH, Armelagos GJ: Factors affecting the distribution of enamel hypoplasias within the human permanent dentition. Am J Phys Anthropol 1985;68:479-493.

-Goodman AH, Martinez C, Chavez A: Nutritional supplementation and the development of linear enamel hypoplasias in children from Tezonteopan, Mexico. Am J Clin Nutr 1991; 53:773-781.

Harris SS, Navia JM: Vitamin A deficiency and caries susceptibility of rat molars. Arch Oral Biol 1980;25:415-421.

-Infante PF, Gillespie GM: Dental caries experience in the deciduous dentition of rural Guatemalan children ages 6 months to 7 years. J Dent Res 1976;55:951-957.

-Infante PF, Gillespie GM: Enamel hypoplasia in relation to caries in Guatemalan children. J Dent Res 1977;56:493-498.

-Johansson I, Ericson T, Bowen W, Cole M: The effect of malnutrition on caries development and saliva composition in the rat. J Dent Res 1985;64:37-43.

Johansson I, Ericson T, Steen L: Studies of the effect of diet on saliva secretion and caries development: The effect of fasting on saliva composition of female subjects. J Nutr 1984;114: 2010-2020.
Johansson I, Lenanderer-Lumikari M, Saellstrom AK: Saliva composition in Indian children with chronic protein-energy malnutrition. J Dent Res 1994;73:11-19.

Johansson I, Saellstrom AK, Rajan BP, Parameswaran A: Salivary flow in dental caries in Indian children suffering from chronic malnutrition. Caries Res 1992;26:38-43.

Jontell M, Linde A: Nutritional aspects on tooth formation. World Rev Nutr Diet 1986;48: 114-136.

Kanawati AA, McLaren DS: The effect of proteincalorie malnutrition on prediction of age by number of erupted deciduous teeth: Experience in Lebanon. J Trop Pediatr 1973;19:232233.

Kanchanakamol U, Tuongratanaphan S, Tuongratanaphan S, Lertpoonvilaikul W, Chittaisong C, Pattanaporn K, Navia JM, Davies GN: Prevalence of developmental enamel defects and dental caries in rural pre-school Thai children. Community Dent Health 1996;13:204207.

Leone CW, Oppenheim FG: Physical and chemical aspects of saliva as indicators of risk for dental caries in humans. J Dent Educ 2001;65:10541062 .

Li Y, Navia JM, Bian JY: Caries experience in deciduous dentition of rural Chinese children 3-5 years old in relation to the presence or absence of enamel hypoplasia. Caries Res 1996; 30:8-15.

McGregor IA, Thomson AM, Billewicz WZ: The development of primary teeth in children from a group of Gambian villages, and critical examination of its use or estimating age. $\mathrm{Br} \mathrm{J}$ Nutr 1968;22:307-314.

McMurry DN, Rey H, Casazza LJ, Watson RR: Effect of moderate malnutrition on concentrations of immunoglobulins and enzymes in tears and saliva of young Columbian children. Am J Clin Nutr 1977;30:1944-1948.

Matee M, van't Hof M, Maselle S, Mikx F, van Palenstein HW: Nursing caries, linear hypoplasia, and nursing and weaning habits in Tanzanian infants. Community Dent Oral Epidemiol 1994;22:289-293.

Matee MI, Mikx FH, Maselle SY, Van Palenstein Helderman WH: Rampant caries and linear hypoplasia (short communication). Caries Res 1992;26:205-208.

May RL, Goodman AH, Meindl RS: Response of bone and enamel formation to nutritional supplementation and morbidity among malnourished Guatemalan children. Am J Phys Anthropol 1993;92:37-51.

Mellanby H: The effect of maternal dietary deficiency of vitamin A on the dental tissues in rats. J Dent Res 1942;20:489-509.

Menaker L, Navia JM: Effect of undernutrition during the perinatal period on caries development in the rat. II. Caries susceptibility in underfed rats supplemented with protein or caloric additions during the suckling period. J Dent Res 1973a;52:680-687.
Menaker L, Navia JM: Effects of undernutrition during the perinatal period on caries development in the rat. III. Effects of undernutrition on biochemical parameters in the developing submandibular salivary gland. J Dent Res 1973b;52:688-691.

Menaker L, Navia JM: The effect of undernutrition during the perinatal period on caries development in the rat, changes in whole saliva volume and protein content. J Dent Res 1974; 53:592-597.

Mukherjee DK: Deciduous dental eruption in low income group Bengalia Hindu children. J Trop Pediatr 1973;19:207-210.

Neil JJ, Gurney JM, Kuti OR, Doherty-Akinkuge D, Hanafy MN, Kassem SA, et al: Deciduous dental eruption time and protein-calorie malnutrition from different parts of the world. J Trop Pediatr 1973;19:217-222.

Nikiforuk G, Fraser D: The etiology of enamel hypoplasia: A unifying concept. J Pediatr 1981; 98:888-893.

Onis M, Monteiro C, Akre J, Clugston G: The worldwide magnitude of protein-energy malnutrition: An overview from the WHO Global Database on Child Growth. Geneva, WHO, 2001.

Pascoe L, Seow WK: Dental caries and enamel hypoplasia in Australian aboriginal children. Pediatr Dent 1994;16:194-199.

Rami Reddy V: Eruption of deciduous teeth among the children of Gulbarga, South India. Indian J Med Res 1981;73:772-781.

Rami Reddy V, Vijayalakshmi PB, Chandrasekhar $\mathrm{RB}$ : Deciduous tooth emergence and physique of Velema children of Southeastern Andhra Pradesh, India. Acta Odontol Pediatr 1986; 7 : $1-5$.

Robinow M: The eruption of deciduous teeth (factors involved in timing). J Trop Pediatr 1973; 19:200-205.

Robinson C, Shore RC, Brookes SJ, Strafford S, Wood SR, Kirkhom J: The chemistry of enamel caries. Crit Rev Oral Biol 2000;11:481495 .

Rugg-Gunn AJ, Al-Mohammadi SM, Butler TJ: Malnutrition and developmental defects of enamel in 2- to 6-year-old Saudi boys. Caries Res 1998;32:181-192.

Schamschula RG, Cooper MH, Adkins BL, Barnes DE, Agus HM: Oral conditions in Australian children of Aboriginal and Caucasian descent. Community Dent Oral Epidemiol 1980;8: 365-369.

Semba RD, Bloem MW: Nutrition in Health in Developing Countries. Totowa, Humana Press, 2001

Seow WK: Biological mechanisms of early childhood caries. Community Dent Oral Epidemiol 1998;26:8-27.

Shaw JH, Griffiths D: Dental abnormalities in rats attributable to protein deficiency during reproduction. J Nutr 1963;80:123-141.

Shils ME, Olson JA, Moshe S: Modern Nutrition in Health and Disease. Philadelphia, Lippincott, Williams \& Wilkins, 1999. 
Suckling G, Elliott DC, Thurley DC: The production of developmental defects of enamel in the incisor teeth of penned sheep resulting from induced parasitism. Arch Oral Biol 1983;28: 393-399.

- Sweeney EA, Cabrera J, Urrutia J, Mata L: Factors associated with linear hypoplasia of human deciduous incisors. J Dent Res 1969;48:12751279.

- Sweeney EA, Guzman M: Oral conditions in children from three highland villages in Guatemala. Arch Oral Biol 1966;11:687-698.

- Sweeney EA, Saffir AJ, De LR: Linear hypoplasia of deciduous incisor teeth in malnourished children. Am J Clin Nutr 1971; 24:29-31.
Toverud G: The influence of war and post-war conditions on the teeth of Norwegian school children: Eruption of permanent teeth and status of deciduous dentition. Milbank Mem Fund Q 1956;34:355-430.

Truswell AS, Hansen DL: Eruption of deciduous teeth in protein-calorie malnutrition. J Trop Pediatr 1973;19:214-216.

UNICEF: Unmasking Malnutrition. UNICEF, 1995.

UNICEF: The Progress of Nations. UNICEF, 1999.

USDA: Questions and answers about household food security in the United States, 1999. USDA, 2000, www.ers.usda.gov/publications/ fanrr8/qa.
Visweswara R, Shusheela TP, Swaminathan MC: Association of growth status and deciduous teeth eruptions among rural Indian children. J Trop Pediatr 1973;19:223-227.

-Watson RR, Antal M: Effect of moderate chronic protein deficiency on rat salivary components. J Nutr 1980;110:771-777.

WHO: Child Malnutrition. Geneva, WHO, 1996.

WHO: Oral Health Surveys: Basic Methods. Geneva, WHO, 1997.

Wiecha JL, Casey VA: High prevalence of overweight and short stature among Head Start children in Massachusetts. Public Health Rep 1994; 109:767-773.

Winick M, Noble A: Cellular response in rats during malnutrition at various ages. J Nutr 1966; 89:300-306. 